\title{
EFFECT OF SIMULATED GASTRIC ACID ON OPTICAL PROPERTIES OF DIFFERENT MONOLITHIC CERAMICS
}

\author{
Mohamed F Aldamaty ${ }^{*}$, Khaled M Haggag ${ }^{* *}$, Hesham I Othman **
}

\begin{abstract}
Objective: The purpose of this study was to evaluate the effect of simulated gastric acid on the color and translucency of monolithic ceramics. Materials and Methods: A total of forty ceramic disks made from four ceramic materials (10 each) were cut with a final thickness of $1.0 \mathrm{~mm}$ using Isomet saw from ceramic blocks of each material (Ceramil Zolid fx white [Z], IPS e.max CAD [E] HT A3, Vita Suprinity [S] HT A3, and Cerasmart [C] HT A3). Zirconia disks were then colored using A3 coloring liquid and sintered, while IPS e.max CAD and Vita Suprinity were crystallized according to their manufacturers' instructions. A spectrophotometer was used to evaluate color change $(\Delta \mathrm{E})$ and translucency parameter $(\mathrm{TP})$. $\mathrm{L}^{*} \mathrm{a} * \mathrm{~b} *$ color coordinates were determined over white and black backgrounds according to the CIE Lab 1976 color scale before and after immersion in simulated gastric acid $(\mathrm{HCl})$ for $96 \mathrm{~h}$ at $37^{\circ} \mathrm{C}$ incubator. Collected data were statistically analyzed using ANOVA followed by Tukey's posthoc test and the significance level was set at $\mathrm{P} \leq 0.05$. Results: The highest color change was recorded for group $\mathrm{C}$ followed by group E, group $\mathrm{S}$, and the least change was with group $\mathrm{Z}$. Translucency increased significantly $(\mathrm{P}<0.05)$ after acid immersion for all materials except for group C. Conclusion: Zolid fx showed the greatest color stability after gastric acid immersion, while Cerasmart is the least one, however, all tested ceramics are within the clinically acceptable limit. Translucency increased after gastric acid immersion for all tested ceramics except for Cerasmart, it decreased.
\end{abstract}

KEYWORDS: Color Stability, Gastric Acid, GERD, Monolithic Ceramics, Translucency.

\section{INTRODUCTION}

With the increasing demand for esthetic restorations, the possibility to produce full contour crowns, and the assumed enhancements in bonding ability, different monolithic restorations have gained attention as a suitable material for restoring worn dentition. Dental erosion is considered one of the main factors of tooth wear in which loss of tooth structure occurs by acids due to non-bacterial causes ${ }^{(1)}$.

The continuous acid attack renders the tooth surface to be susceptible to more abrasive wear. These erosive acids can be caused by intrinsic origin as in stomach acid, or extrinsic as that of acidic beverages and citrus fruits ${ }^{(2)}$. Gastric acid has lower $\mathrm{pH}$ and more erosive ability than dietary acids, hence the amount of destruction is unfortunately more severe ${ }^{(3)}$.

The main intrinsic source of acid is from the stomach. Gastric contents are very acidic and were reported to have a $\mathrm{pH}$ as low as 1 . Gastric contents can travel up into the oral cavity by vomiting and regurgitation which is commonly associated with gastroesophageal reflux disease (GERD) (4). Regurgitation is the involuntary movement of the gastric contents from the stomach to the oral

* Assistant Lecturer, Crown and Bridge Department, Faculty of Dental Medicine, Al-Azhar University, (Boys-Cairo), Egypt.

** Professor, Crown and Bridge Department, Faculty of Dental Medicine, Al-Azhar University, (Boys-Cairo), Egypt.

-Corresponding author: dr.damaty86@gmail.com 
cavity. Regurgitation is different from vomiting as it does not involve nausea, retching, or abdominal contractions. The contents that are regurgitated include hydrochloric acid, undigested food particles, bile acids, and trypsin ${ }^{(3)}$.

GERD is a common medical condition causing involuntary gastric acid movement into the oral cavity. It is a relatively common condition worldwide, with prevalence rates in adults ranging from $21 \%$ to $56 \%$ in different countries; $15 \%$ of individuals experience heartburn once a week; $7 \%$ to $10 \%$ experience heartburn once daily; $25 \%$ to $40 \%$ of Americans experience symptomatic GERD at some point; $45 \%$ to $85 \%$ of women experience GERD or heartburn during pregnancy ${ }^{(5,6)}$.

Dentists are commonly the first to diagnose GERD through erosion of teeth because most people are not aware of the presence of the disease, as it was reported that; there is a correlation between dental erosion and GERD patients where patients with GERD are then found to have dental erosion and patients with dental erosion are then found to have GERD ${ }^{(7)}$.

The high acidity of the gastric components reaching the oral cavity is likely to cause more dental erosion compared with carbonated drinks ${ }^{(8)}$. Unlike dental caries, in which the demineralization is caused by an acidic environment produced by plaque bacteria, the acidic environment in GERD is due to the reflux of hydrochloric acid from the stomach. The erosive effect tends to be localized on the palatal aspects of the maxillary teeth; however, it can also extend to the occlusal and other surfaces of the dentition ${ }^{(9,10)}$.

Although dental ceramics can provide the most natural replacements for teeth and are considered chemically inert, many factors such as the composition, microstructure, chemical properties of the ceramic materials, erosive or acidic agents, exposure time, and the temperature, may influence the durability of dental ceramics ${ }^{(11)}$.
Several previous studies have reported the degradation of dental ceramics when exposed to aqueous solutions or acidic agents ${ }^{(12-14)}$. This condition results from selective releasing of alkaline ions, which are far less stable in the glassy phase than in the crystalline phase of dental ceramics ${ }^{(12-14)}$. The consequences of ceramic degradation are coarseness of the exposed surface, increase in plaque accumulation, wear to antagonist materials or teeth, and discoloration of restorations ${ }^{(12-15)}$.

According to the international standard ISO 6872 for dental ceramics, $4 \%$ acetic acid at $80^{\circ} \mathrm{C}$ for $16 \mathrm{~h}$ is used when chemical solubility is determined (16). By using acetic acid, the chemical solubility test and aging of the specimens could be performed at the same time. But to simulate in vivo condition, a stronger acid ( $\mathrm{HCl}, \mathrm{pH} 1.2)$ was used as an ageing solution by previous studies ${ }^{(17,18)}$ rather than the ISO standard 6872 of $4 \%$ acetic acid. Also, the immersion time was increased to $96 \mathrm{~h}$ at $37^{\circ} \mathrm{C}$, which is supposed to simulate over 10 years of clinical exposure in-vivo ${ }^{(17)}$.

Sulaiman et al. ${ }^{(17)}$ studied the impact of gastric acid $(\mathrm{pH} 1.2)$ on optical properties of different monolithic zirconia and IPS e.max and found that IPS e.max and FSZ (fully stabilized zirconia) exhibited a significant increase in translucency and surface gloss after acid immersion. While Kulkarni et al. ${ }^{(6)}$ found that zirconia showed resistance to gastric acid and tooth brushing, whereas the gastric acid treatment affected the color and surface gloss of feldspathic porcelain and IPS e.max, but the translucency for all materials was not statistically significant. Furthermore, in another study, the color stability of Vita Suprinity was affected by citric acid (pH 2) than artificial saliva ${ }^{(19)}$.

Resistance to chemical degradation of dental materials is a principal requirement for intra-oral use and is a relevant concern in choosing ceramic materials for restorations. Dental prostheses must resist degradation over both intermittent and constant exposure to harsh conditions arising 
from temperature changes and acid-base shifts ${ }^{(12)}$. Polymer-based materials may be more sensitive to aging factors than monolithic ceramics due to the infiltrated polymer and a large number of polymer/particle interfaces ${ }^{(20)}$. However, information considering the degradation of the recently developed materials under variation in $\mathrm{pH}$ conditions is limited. Therefore, the study was designed to evaluate the effect of simulated gastric acid on the color stability and translucency of different monolithic ceramic materials.

\section{MATERIALS AND METHODS}

The materials used in this study were group Z; Ceramil Zolid fx white (Amann Girrbach, Koblach, Austria), group E; IPS e.max CAD HT A3 (Ivoclar Vivadent AG, Schaan, Liechtenstein), group S; Vita Suprinity HT A3 (Vita Zanfabrik, Germany), and group C; Cerasmart HT A3 (GC, Tokyo, Japan). A total of 40 disks from four ceramic materials (10 each) with a thickness $1.0 \mathrm{~mm}$ were cut from the ceramic blocks for each material, except for zirconia, the disks were cut $20 \%$ larger to compensate for shrinkage after sintering.

Cuts were made using a low-speed diamond saw (Isomet saw 4000, Buehler, Illinois Tool Works Inc, USA) running under water coolant with $2500 \mathrm{rpm}$ speed. A digital caliper (Fisher Scientific Traceable Caliper, USA) was used to confirm the thickness of the specimens after sawing.

The uncolored zirconia disks cut from white Zolid fx blanks were colored, before sintering, in Ceramill FX coloring liquid shade A3 ( Amann Girrbach, Koblach, Austria) for cubical zirconia according to manufacturer's instruction. The dipping technique was used; in which the disks were immersed into the coloring liquid for 10 seconds to absorb the color, then removed by a pair of plastic tweezers.

After coloring and before sintering, zirconia disks were pre-dried at a temperature of $80^{\circ} \mathrm{C}$ for 60 minutes. Then, the specimens were sintered at a temperature of $1450^{\circ} \mathrm{C}$ in the high-temperature furnace (Ceramill Therm, Amann Girrbach AG, Herrschaftswiesen 16842 koblach, Austria) according to the manufacturer's instructions.

Ceramic disks of IPS e.max CAD and Vita Suprinity were crystallized in the Programat P310 furnace (Programat P310, Ivoclar Vivadent AG, Bendererstrasse 2, FL-9494 Schaan, Liechtenstein) with the specific program for each material according to manufacturer's instructions. The disks of the Cerasmart material didn't need any further heat treatment, they were just polished and cleaned.

Polishing of specimens was done on one surface using Robinson's brush and polishing paste (Pearl Surface Z). After polishing, all specimens were cleaned in an ultrasonic cleaner (Silfradent, Santa Sofia, Forli-Cesena, Italy) in a distilled water bath for 10 minutes, then left to air-dry over an absorbent paper.

After ultrasonic cleaning, all ceramic disk specimens were weighed before and after gastric acid immersion by a micro-scale (AXIS Sp. z o.o. ul. Kartuska 375B, 80-125 Gdańsk, pomorskie, Poland).

A generic formula simulating gastric acid was used. Hydrochloric acid ( $\mathrm{HCl})$ of $0.06 \mathrm{M}(\mathrm{pH} 1.2)$ was prepared according to previous studies ${ }^{(17,18)}$. The $\mathrm{pH}$ was monitored with $\mathrm{pH}$-meter (JENCO, Model No. 6173pH, SN. JC05788, made in China for JENCO USA) and the solution changed every $24 \mathrm{~h}$. Each ceramic disk was immersed individually with a polished surface facing up in $5 \mathrm{ml}$ of the simulated gastric acid for $96 \mathrm{~h}$ at $37^{\circ} \mathrm{C}$ in an incubator (Memmert, GmbH Co. KG, Schwabach, Germany).

Before and after immersion in the acid, $\mathrm{L}^{*} \mathrm{a} * \mathrm{~b}^{*}$ color coordinates were determined over white and black backgrounds by using a spectrophotometer (JASCO Corporation, V570, Tokyo, Japan) according to the CIE $1976 \mathrm{~L}^{*} \mathrm{a} * \mathrm{~b} *$ color scale relative to the CIE standard illuminant D65 
(as defined by the International Commission on Illumination) which corresponds to "average" daylight.

The color change $(\Delta \mathrm{E})$ of each ceramic disk was obtained by calculating the color difference of the disk against the white background (w) before and after acid immersion according to the following equation:

$$
\begin{aligned}
& \Delta \mathrm{E}=\left(\left[\Delta \mathrm{L}^{*}\right]^{2}+\left[\Delta \mathrm{a}^{*}\right]^{2}+\left[\Delta \mathrm{b}^{*}\right]^{2}\right)^{1 / 2} \\
& \Delta \mathrm{E}=\left(\left[\mathrm{L}_{\text {after }}-\mathrm{L}_{\text {before }}\right]^{2}+\left[\mathrm{a}_{\text {affer }}-\mathrm{a}_{\text {before }}\right]^{2}+\left[\mathrm{b}_{\text {affer }}-\mathrm{b}_{\text {before }}\right]^{2}\right)^{1 / 2}
\end{aligned}
$$

The translucency parameter (TP) values were evaluated by calculating the color difference of each ceramic disk over black and white backgrounds before and after acid immersion according to the following equation:

$$
\mathbf{T P}=\left(\left[\mathrm{L}_{\mathrm{b}}^{*}-\mathrm{L}_{\mathrm{w}} *\right]^{2}+\left[\mathrm{a}_{\mathrm{b}}^{*}-\mathrm{a}_{\mathrm{w}}^{*}\right]^{2}+\left[\mathrm{b}_{\mathrm{b}}^{*}-\mathrm{b}_{\mathrm{w}} *\right]^{2}\right)^{1 / 2}
$$

Where $\mathrm{L}^{*}$ refers to the lightness, $\mathrm{a}^{*}$ to redness to greenness, and $b^{*}$ to yellowness to blueness. Letters " $b$ " and "w" refer to color coordinates over the black and white backing, respectively.

All raw data were collected and tabulated then represented in mean and standard deviation. Statistical analysis was performed by using computer software (SPSS V 20.0, SPSS Inc., IBM Corporation, NY, USA) for windows. The data was analyzed using One-way ANOVA followed by the Tukey post hoc test with $\mathrm{P} \leq 0.05$ significance level.

\section{RESULTS}

One-way ANOVA was conducted between groups to compare the effect of treatment (gastric acid immersion) on optical characteristics (color and translucency) for the four types of ceramics [zirconia (Z), IPS e.max CAD (E), vita Suprinity (S) and Cerasmart (C)]. A Tukey post hoc test was used to show significance between pairs of groups. The significance level was set at $\mathrm{P} \leq 0.05$ with $95 \%$ Confidence Interval for the mean values.

\section{Color Change $(\Delta \mathrm{E})$ :}

There was a statistically significant difference $(\mathrm{P}<0.05)$ between all groups except between $\mathrm{E}$ and $\mathrm{S}$ groups, there was no statistically significant difference $(\mathrm{P}>0.05)$. The highest color change was recorded for group $\mathrm{C}$ followed by group $\mathrm{E}$, group $\mathrm{S}$, and the least one is group Z. Table (1), Figure (1).

TABLE (1): $\triangle$ E comparison among different materials:

\begin{tabular}{|c|c|c|c|}
\hline Group & Mean $(\Delta \mathbf{E})$ & SD & P-value \\
\hline $\mathbf{Z}$ & $1.31^{\mathrm{a}}$ & 0.32 & \multirow{2}{*}{$0.00^{*}$} \\
\hline $\mathbf{E}$ & $2.02^{\mathrm{b}}$ & 0.52 & \\
\cline { 1 - 3 } $\mathbf{S}$ & $1.95^{\mathrm{b}}$ & 0.43 & \\
\cline { 1 - 3 } $\mathbf{C}$ & $2.59^{\mathrm{c}}$ & 0.29 & \\
\hline
\end{tabular}

Same letters mean non-significant, different letters mean significant, $\left({ }^{*}\right)$ Significant $P \leq 0.05$

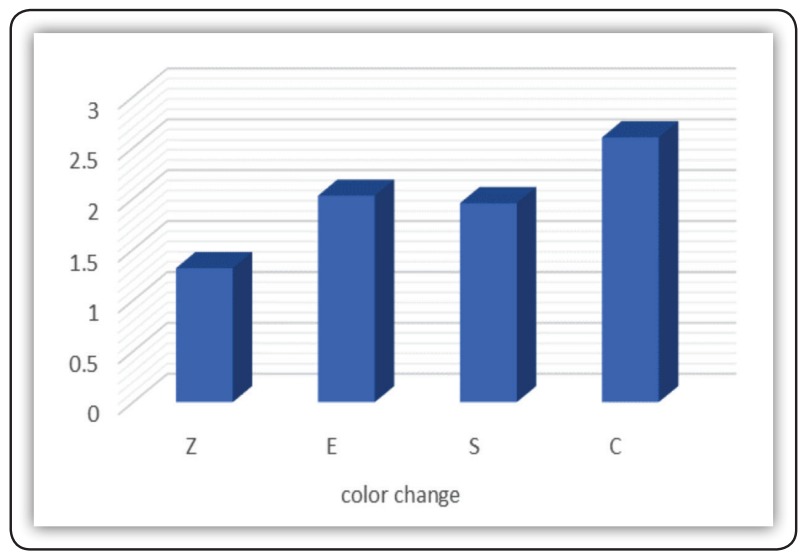

FIG (1) A column chart showing color change among different materials

\section{Translucency Parameter (TP):}

There was a statistically significant difference $(\mathrm{P}<0.05)$ for each ceramic material after acid immersion. But there was no significant difference $(\mathrm{P}>0.05)$ between $\mathrm{Z}$ and $\mathrm{E}, \mathrm{E}$ and $\mathrm{S}$ before acid immersion, and between $\mathrm{Z}$ and $\mathrm{E}, \mathrm{E}$ and $\mathrm{S}, \mathrm{Z}$ and $\mathrm{S}$ after acid immersion, while the remaining comparisons were significant $(\mathrm{P}<0.05)$. Table $(2)$, Figure (2) 
- For group Z; translucency increased significantly after acid immersion.

- For group E; translucency increased significantly after acid immersion.

- For group S; translucency increased significantly after acid immersion.

- For group $\mathrm{C}$; translucency decreased significantly after acid immersion.

TABLE (2): TP comparison before and after acid immersion between different materials:

\begin{tabular}{|c|c|c|c|c|c|c|}
\hline \multirow{2}{*}{ Group } & \multicolumn{3}{|c|}{ Before } & \multicolumn{3}{c|}{ After } \\
\cline { 2 - 3 } & Mean & SD & P-value & Mean & SD & P-value \\
\hline Z & $0.53^{\mathrm{a}}$ & 0.15 & & $0.84^{\mathrm{d}}$ & 0.13 & \\
\cline { 1 - 2 } E & $0.43^{\mathrm{ab}}$ & 0.05 & \multirow{2}{*}{$0.0000^{*}$} & $0.85^{\mathrm{d}}$ & 0.21 & \multirow{2}{*}{$0.0004^{*}$} \\
\cline { 1 - 2 } S & $0.41^{\mathrm{b}}$ & 0.04 & & $0.83^{\mathrm{d}}$ & 0.16 & \\
\cline { 1 - 2 } C & $0.72^{\mathrm{c}}$ & 0.19 & & $0.53^{\mathrm{e}}$ & 0.11 & \\
\hline
\end{tabular}

Same letters mean non-significant,

different letters mean significant,

(*) Significant $P \leq 0.05$

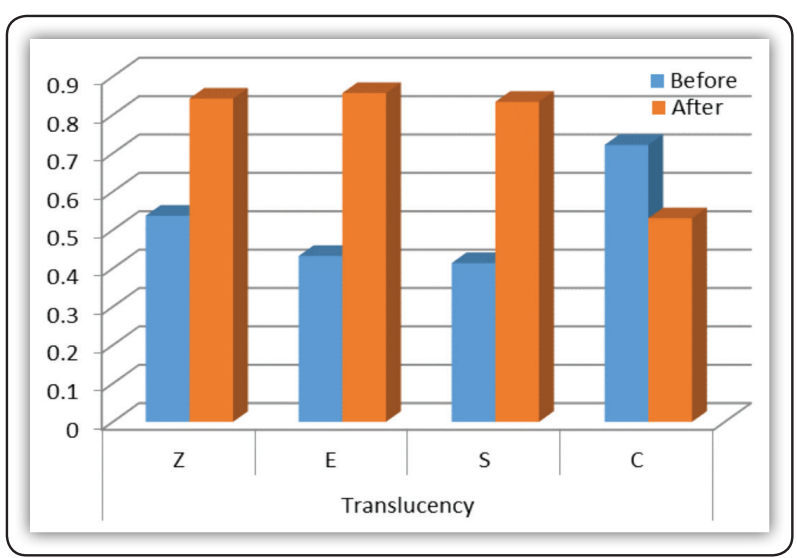

FIG (2) Bar chart showing TP comparison among different materials before and after acid immersion.

\section{DISCUSSION}

Dental ceramics present excellent physical and mechanical properties, such as biocompatibility with oral tissues, provided that the material is placed in an optimal environment. Thus, it has become the material of choice for replacing dental structures. However, an aqueous environment and exposure to chemical solutions may create micro-cracks, resulting in increased surface roughness which would adversely affect color and light reflection of the material ${ }^{(21,22)}$.

Dental professionals usually review health histories and medications that identify patients with a diagnosis of acid reflux. Most often, a specialized physician known as a gastroenterologist treats this condition, however, there are dental manifestations to it, so it is important that dental professionals identify these patients and recommend appropriate dental treatment to protect the long-term health of the dentition. Furthermore, dental professionals could recognize this condition in untreated patients and may need to refer those patients to a physician for further evaluation.

Oral symptoms associated with GERD are burning mouth syndrome, dental erosion and sensitivity, loss of vertical dimension, and esthetic problems. If tooth structure loss reaches such level of high severity, functional and esthetic rehabilitation of the teeth becomes necessary ${ }^{(23)}$.

If a GERD patient, or similar conditions, needs dental restorative treatment, the clinician must consider the effect of acid on the intended restorative material that will be used, consequently, the choice of an adequate restorative material plays an extremely relevant role in the durability of the restoration. Therefore, this study was conducted to clarify this issue in terms of color stability and translucency.

The ceramic materials used in this study were selected according to the availability in the market and the popularity of their use to represent their 
families. The ceramic materials were just polished then tested without glazing to determine the effect of gastric acid on the ceramic material itself, as the glaze layer is removed or peeled off after about six months ${ }^{(24)}$. Furthermore, several studies have shown that polishing methods can result in a final ceramic surface with a similar or better roughness than glaze-fired ceramic surfaces ${ }^{(25,26)}$.

In the present study the ceramic materials were sectioned with the high precision saw Isomet 4000, which ensures a standardized thickness for all specimens, thus avoiding any optical alterations that could occur due to change in thickness ${ }^{(27)}$. Polishing was performed for the specimens regarding the evidence proving that stain resistance and color stability is improved with properly polished surfaces ${ }^{(28)}$.

Regarding the corrosive acid concentration and immersion time, there is no clear agreement in the literature of the actual method of acid simulation and the equivalent time to replicate an in-vivo model (17). The ISO standard 6872 solubility test for dental ceramics advocates the use of a $4 \%$ acetic acid and a standard exposure time of $16 \mathrm{~h}$ at $80^{\circ} \mathrm{C}{ }^{(16)}$. The in-vivo relevance of this time was determined to be equivalent to approximately 2 years clinical situation based on the study by De Rijk et al. ${ }^{(29)}$ who reported that immersion in artificial saliva at $22^{\circ} \mathrm{C}$ for 22 years would have been required to produce the same degree of dissolution as exposure to $4 \%$ acetic acid at $80^{\circ} \mathrm{C}$ for $168 \mathrm{~h}$.

The in-vitro simulation of corrosive effects of acids on the dental ceramics mainly depends on the concentration of the acid, the time of immersion, and the temperature. In the present study, a stronger acid $(\mathrm{HCl}, \mathrm{pH}$ 1.2) was used as an ageing solution based on previous studies ${ }^{(17,18)}$ rather than the ISO standard 6872 of $4 \%$ acetic acid to represent the clinical situation of patients who have acid reflux disease. Also, the immersion time was increased to $96 \mathrm{~h}$ at $37^{\circ} \mathrm{C}$, which is supposed to simulate over 10 years of clinical exposure in-vivo ${ }^{(17)}$.
The risk of these acids lies in its chelating effect that can cause degradation, ionic dissolution and release of alkaline lithium and aluminum ions, which are less stable in the glassy phase than in the crystalline phases, and results in the dissolution of the ceramic silicate network, which can be toxic ${ }^{(12)}$.

Optical characteristics in the present study were evaluated according to the CIELab system using a spectrophotometer on flat ceramic disks. This device might have a disadvantage of being less accurate when measuring a curved surface which did not apply in the present study. Spectrophotometers have good accuracy and reproducibility and are used as a viable instrument in dentistry to obtain a proper shade selection and in research to assess the color stability of dental restorations. Furthermore, the validation of this method was verified by many previous studies ${ }^{(30,31)}$.

For this study, it was considered more realistic to set the clinically acceptable limit at $3.7 \Delta \mathrm{E}$ that has been referenced for many years by previous studies $^{(32,33)}$.

In the present study; color parameters and translucency of the four ceramic materials used were made using a spectrophotometer, both before and after immersion in simulated gastric acid for 96 hours at $37^{\circ} \mathrm{C}$ incubator.

For color change $(\Delta \mathrm{E})$, there was a statistically significant difference $(\mathrm{P}<0.05)$ among different groups, except between $\mathrm{E}$ and $\mathrm{S}$ groups, which had no statistically significant difference $(\mathrm{P}>0.05)$.

Although the highest color change was recorded for group $\mathrm{C}$ followed by group $\mathrm{E}$, group $\mathrm{S}$, and the least one is group Z, all results were within the clinically acceptable limit $(3.7 \Delta \mathrm{E})$ which was set for this study.

Zolid fx (group Z) showed the least color change $(1.31 \Delta \mathrm{E})$. This may be due to the high stability of the fully stabilized cubic form which has more 
aging resistance than partially stabilized zirconia ${ }^{(34)}$. While Cerasmart (group C) showed the highest color change (2.59 $\Delta \mathrm{E})$, it may be due to its resin matrix composition. This may be attributed to that the staining susceptibility of ceramics is directly related to the degree of water sorption. Their ability to absorb water can also absorb fluid with pigments, thus acting as a vehicle for stain penetration into the bulk of the material(35).

For translucency parameter (TP) there was a statistically significant difference $(\mathrm{P}<0.05)$ for each ceramic material after acid immersion, where translucency was increased significantly after acid immersion for Z, E, and S groups, while decreased significantly for group $\mathrm{C}$.

Zolid fx and IPS e.max showed smoother surface after acid immersion, so it is logically to be more translucent, as a rough surface would adversely affect the color and light reflection of a restoration, since the higher the roughness, the lower the optical reflection would be ${ }^{(22)}$. Also, it is worth mentioning that translucency of Zolid $\mathrm{fx}$ in the present study was comparable to IPS e.max before and after acid immersion which confirms the claim of the manufacturer.

Although Vita Suprinity showed a rougher surface after acid exposure ${ }^{(19,36)}$, it displayed more translucency. This is maybe the result of its high glass content and lithium silicate crystals that offer the material with its superior optical characteristics ${ }^{(37)}$.

On the other hand, Cerasmart showed a significant decrease in translucency after acid immersion. This is in consistent with the highest color change observed with this material due to its resin content.

The absorption features of the resin allow the acid to attack the bond between glass particles and the polymer, leading to the disintegration of the polymer and degradation of the ceramic, leaving a rough surface behind, which adversely affects the color and light reflection of restoration ${ }^{(15,20,38)}$.

The translucency results of the present study are in agreement with those of Sulaiman et al., ${ }^{(21)}$ but are in disagreement with Kulkarni et al. ${ }^{(8)}$ which found no statistically significant effect on dental ceramics (feldspathic porcelain, IPS e.max CAD, and monolithic zirconia) after gastric acid treatment. This may be due to the different methodology, $\mathrm{pH}$, and immersion time used in their study, as they immersed samples in gastric acid $(\mathrm{pH} 2)$ for 2 minutes then rinsed with deionized water for 2 minutes, where the procedure was repeated 6 times per day for 9 days.

The limitation of this study is the absence of testing ceramic materials against different colored solutions with different $\mathrm{pH}$, which can contribute to having more understanding of the optical properties and corresponding behavior of ceramic materials.

As most monolithic crowns are stained and glazed, it would be interesting to further evaluate the effect of an acidic environment on the stability of such stains and how the esthetic appearance of a restoration is affected. Also, the effect of an acidic environment on the flexural strength of ceramic materials should be further investigated.

\section{CONCLUSION}

Within the limitation of this in-vitro study, the following can be concluded;

1. Zolid fx showed the greatest color stability after gastric acid immersion, while Cerasmart is the least stable among tested materials. However, all tested ceramics are within the clinically acceptable limit.

2. Translucency increased after gastric acid immersion for all tested ceramics except for Cerasmart, it decreased. 


\section{REFERENCES}

1. Sapp JP, Eversole LR, Wysocki GP. Contemporary oral and maxillofacial pathology. $2^{\text {nd }}$ ed. St. Louis: Mosby; 2004.

2. Lussi A, Jäggi T. Erosion-diagnosis and risk factors. Clin oral invest 2008 Mar; 12(1):5-13.

3. Moazzez R, Bartlett D. Intrinsic causes of erosion. In: Lussi A, Ganss C, editors. Erosive tooth wear: from diagnosis to therapy. Basel: Karger medical and scientific publishers; 2014; 360-442.

4. Loke C, Lee J, Sander S, Mei L, Farella M. Factors affecting intra-oral $\mathrm{pH}$-a review. J Oral Rehab 2016 Oct; 43(10):778-85.

5. Dundar A, Sengun A. Dental approach to erosive tooth wear in gastroesophageal reflux disease. Afr Health Sci. 2014 Jun;14(2):481-6.

6. Kulkarni A, Rothrock J, Thompson J. Impact of Gastric Acid Induced Surface Changes on Mechanical Behavior and Optical Characteristics of Dental Ceramics. J Prosthodont. 2020 Mar; 29(3):207-18.

7. Pace F, Pallotta S, Tonini M, Vakil N, Bianchi Porro G. Systematic review: gastro-oesophageal reflux disease and dental lesions. Aliment Pharmacother 2008 Jun; 27(12):1179-86.

8. Bartlett DW, Coward PY. Comparison of the erosive potential of gastric juice and a carbonated drink in vitro. J Oral Rehabil. 2001 Nov; 28(11):1045-7.

9. Moazzez R, Bartlett D, Anggiansah A. Dental erosion, gastro-oesophageal reflux disease and saliva: how are they related? J Dent. 2004 Aug; 32(6):489-94.

10. Moazzez R, Anggiansah A, Bartlett DW. The association of acidic reflux above the upper oesophageal sphincter with palatal tooth wear. Caries Res. 2005 Nov-Dec; 39(6):475-8.

11. Milleding P, Haraldsson C, Karlsson S. Ion leaching from dental ceramics during static in vitro corrosion testing. J Biomed Mater Res 2002 Sep; 61(4):541-50.

12. Anusavice KJ. Degradability of dental ceramics. Adv Dent Res 1992 Sep; 6(1):82-9.

13. Kukiattrakoon B, Hengtrakool C, Kedjarune-Leggat U. Chemical durability and microhardness of dental ceramics immersed in acidic agents. Acta Odontol Scand 2010 Jan; 68(1):1-10.

14. Jakovac M, Živko-Babić J, Ćurković L, Carek A. Chemical durability of dental ceramic material in acid medium. Acta stomatol Croat 2006 Mar; 40(1):65-71.
15. Ferracane JL. Hygroscopic and hydrolytic effects in dental polymer networks. Dent Mater 2006 Mar; 22(3):211-22.

16. International Standards for Dental Ceramics. ISO 6872. Geneva, Switzerland: International Organization for Standardization; 1995. In Sulaiman TA, Abdulmajeed AA, Shahramian K, Hupa L, Donovan TE, Vallittu P, Närhi TO. Impact of gastric acidic challenge on surface topography and optical properties of monolithic zirconia. Dent Mater. 2015 Dec; 31(12):1445-52.

17. Sulaiman TA, Abdulmajeed AA, Shahramian K, Hupa L, Donovan TE, Vallittu P, Närhi TO. Impact of gastric acidic challenge on surface topography and optical properties of monolithic zirconia. Dent Mater. 2015 Dec; 31(12):1445-52.

18. Hunt D, McIntyre J. The development of an in vitro model of dental erosion. J Dent Res 1992;71:985.

19. El Sokkary A, Elguindy J, El Shihi O. Effect of Surface Finish and Acidic pH Media on the Surface Roughness and the Color Stability of Zirconium Reinforced Lithium Silicate Glass Ceramics (An In-Vitro Study). Acta Scientific Dental Sciences 2018; 2(3):21-7.

20. Prakki A, Cilli R, Mondelli RF, Kalachandra S, Pereira JC. Influence of $\mathrm{pH}$ environment on polymer based dental material properties. J Dent 2005 Feb; 33(2):91-8.

21. Ccahuana VZ, Özcan M, Mesquita AM, Nishioka RS, Kimpara ET, Bottino MA. Surface degradation of glass ceramics after exposure to acidulated phosphate fluoride. J Appl Oral Sci 2010 Apr; 18(2):155-65.

22. Lee YK, Lim BS, Kim CW. Effect of surface conditions on the color of dental resin composites. J Biomed Mater Res. 2002; 63(5):657-63.

23. Ali DA, Brown RS, Rodriguez LO, Moody EL, Nasr MF: Dental erosion caused by silent gastroesophageal reflux disease. J Am Dent Assoc 2002 Jun; 133(6):734-7.

24. Sulaiman TA, Camino RN, Cook R, Delgado AJ, Roulet J-F, Clark WA. Time-lasting ceramic stains and glaze: A toothbrush simulation study. J Esthet Restor Dent. 2020 Apr; 1-5.

25. Jagger DC \& Harrison A. An in vitro investigation into the wear effects of unglazed, glazed and polished porcelain on human enamel. J Prosthet Dent. 1994 Sep; 72(3):320-3.

26. Sarikaya I, Güler AU. Effects of different polishing techniques on the surface roughness of dental porcelains. J Appl Oral Sci 2010 Feb; 18(1):10-6.

27. Awad D, Stawarczyk B, Liebermann A, Ilie N. Translucency of esthetic dental restorative CAD/CAM materials and composite resins with respect to thickness and surface roughness. J Prosthet Dent. 2015 Jun; 113(6):534-40. 
28. Samra AP, Ribeiro DG, Borges CP, Kossatz S. Influence of professional prophylaxis on reducing discoloration of different aesthetic restorative materials. J Dent 2012 Dec; 40:e71-6.

29. De Rijk WG, Jennings KA, Menis DL. A comparison of chemical durability test solutions for dental porcelains. In: Sauer BW, editor. Biomedical engineering - recent developments. Proceedings of Biomedical Engineering Conference. New York: Pergamon Press, 1985 Jan; p. 152-5.

30. Yu B, Ahn JS, Lee YK. Measurement of translucency of tooth enamel and dentin. Acta Odontol Scand 2009 Jan; 67(1):57-64.

31. Corciolani G, Vichi A. Repeatability of color reading with a clinical and a laboratory spectrophotometer. Int Dent South Africa. 2006; 8(5):62-70.

32. Johnston WM, Kao EC. Assessment of appearance match by visual observation and clinical colorimetry. J Dent Res. 1989 May; 68(5):819-22.

33. Malekipour MR, Sharafi A, Kazemi S, Khazaei S, Shirani F. Comparison of color stability of a composite resin in different color media. Dent Res J. 2012 Jul; 9(4):441-6.

34. Kontonasaki E, Giasimakopoulos P, Rigos AE. Strength and aging resistance of monolithic zirconia: an update to current knowledge. Jpn Dent Sci Rev. 2020 Dec; 56(1):1-23.

35. Arocha MA, Basilio J, Llopis J, Di Bella E, Roig M, Ardu S, Mayoral JR. Colour stainability of indirect CAD-CAM processed composites vs. conventionally laboratory processed composites after immersion in staining solutions. J Dent 2014 Jul; 42(7):831-8.

36. Firouz F, Vafaee F, Khamverdi Z, Khazaei S, Ghorbani Gholiabad S, Mohajeri M. Effect of Three Commonly Consumed Beverages on Surface Roughness of Polished and Glazed Zirconia-Reinforced Lithium Silicate Glass Ceramics. Front Dent. 2019; 16(4):296-302.

37. https://www.vita-zahnfabrik.com/pdb_ ccdc92,27568,85238.html

38. Yu P, Xu Z, Arola DD, Min J, Zhao P, Gao S. Effect of acidic agents on the wear behavior of a polymer infiltrated ceramic network (PICN) material. J Mech Behav Biomed Mater 2017 Oct; 74:154-63. 